\title{
Information Management System based on Principles of Adaptability and Personalization
}

\author{
Ph.D. Dragan Đokić \\ IT \& Electronic Communications \\ Division \\ PE Post of Serbia \\ Belgrade, Serbia
}

\author{
Ph.D. Dragana Šarac \\ Faculty of Technical Sciences \\ University of Novi Sad \\ Belgrade, Serbia
}

\author{
Prof. Ph.D. Dragana Bečejski \\ Vujaklija \\ Faculty of Organizational Sciences \\ University of Belgrade \\ Belgrade, Serbia
}

\begin{abstract}
Among the most significant values of a business system that contribute to its competitiveness in comparison with others, the leading point and the highest value, second to the human factor, is the information at the company's disposal, unified in the company's know how. Unfortunately, the sole awareness of the importance and significance of information is mostly not enough. It is for this reason that this resource is unfairly neglected and is insufficiently used. What results from this situation is that information is mostly unavailable and insufficiently protected. This paper will show one of the possible models of systems for managing information based on principles of adaptability and personalization which aims towards adequate, fast, efficient and secure access to protected information in the company.

The subject of this manuscript is to explore the possibilities of modern information and communication technology application in developing information management system based on principles of adaptability and personalization. The main part of this system is the portal for intelligent document management. The solution proposed in the dissertation is based on integration and implementation of services for adaptation in modern document management systems.
\end{abstract}

Keywords-adaptability; personalization; management information system; business process optimization; collaboration; portals; web services; digital identities; electronic document management

\section{INTRODUCTION}

The transformation of technologies has led to a transformation of the role and the focus of the people in charge in IT firms. The traditional interest in information infrastructure and the functionality of hardware and software components have been directed primarily towards big data, cloud, social networks by current IT experts, ... Nowadays the function of the CIO (chief information officer) takes a higher and a more significant position at the very top of large business systems placing the function holders in the same rank with the strategy decision makers.

This high authority goes with high responsibility. The main items to take care of in big business systems refer to the collaboration of employees, to managing information, to digital transformation and to raising the employees' awareness in relation with significance of information, while being aware of safety and protection of information.
The latest trends in the areas of administration and administrative jobs in large business systems that are engaged in different kinds of business and belong to different industry segments lead to the following general conclusions:

- Most of the companies do not have standards for information exchange. Information is exchanged in different ways: e-mail, LinkedIn, Viber, File servers...;

- Data are stored in different formats, in different mediums and on different locations: as attachments in e-mail clients, as files in folders or in a private cloud...;

- Most employees believe that the current way of information management is not efficient. This is a clear sign that a problem exists (when the employees are aware of it);

- The security and protection of information are not on the satisfactorily high level;

- The steps in the direction of digital transformation have not been started yet;

- Information management training and raising awareness about the importance of information as intellectual capital of company can improve the company's productivity in many ways.

\section{SYSTEMS FOR MANAGEMENT OF INFORMATION}

No matter what activity a large business system is engaged in, is cannot by any means function efficiently without high quality management of information which is itself a result of good and developed information system.

The system for management of information is a comprehensive system, compatible with a variety of software platforms that can be applicable in any business environment. The system for information management does not provide an "in house" solution, but rather starts with an analysis of an organization's needs. In this way, the organization is more flexible regarding technology choice, ways of systematization and standardization of the elements of the system and ways of a solution application [1].

Information management means a daily processing of large amount of electronic and paper documents connecting them with business processes. Information management has its use value in different segments. Besides information processing, 
indexing, metadata adding and storage, it is very important to know what to do with it and to what purpose we can use them. Maximum benefit should be provided for business processes owners in their everyday work.

Also, it is very important how and in which way information is placed depending on the intended outcome. With information filtering, there is a possibility for information selection for employees (according to hierarchy level), business partners or end users. Besides information filtering, it is very important to use new technologies and trends we have at our disposal. In this respect, social networks and different models of cloud computing are increasingly being used. In relation with this topic SaaS emerges, because it offers document management as web, i.e., cloud service.

Current users demand that information should be available from any location (office, vehicle, restaurant...) and from any device (desktop, laptop, PDA, tablet, smart phone...). Modern systems must fulfill these user demands. Such functionality enables comfort and user mobility, but, on the other hand, is potentially a security risk. The danger lies in the fact that unregistered devices from the Internet access intranet information [2].

The implementation of information management system provides optimization at different levels. Figure1.

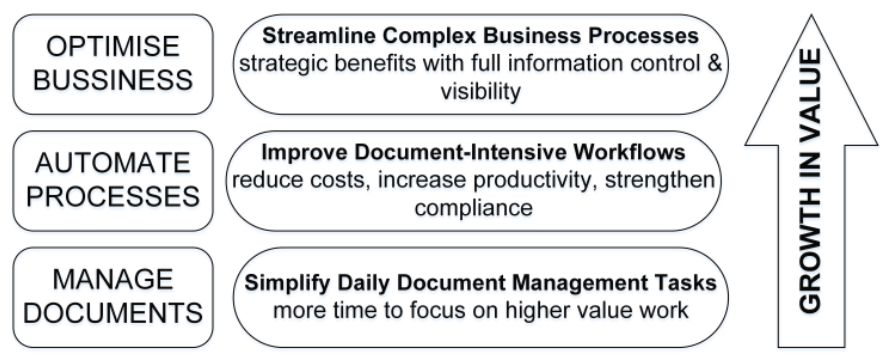

Fig. 1. Information management and optimization levels

\section{TECHNOLOGIES FOR THE DEVELOPMENT OF THE SYSTEM FOR INFORMATION MANAGEMENT}

Basic technologies used for the development of an information management system model in an adaptive and personalized environment are:

- Web portals;

- Digital identity management;

- Adaptive system for information management;

- Business intelligence;

- Key Performance Indicators;

\section{A. WEB Portals}

A large body of research has shown that in modern ebusiness systems, web portals are the best solutions for information management; particularly when there is a need for managing big quantities of heterogenic information.

A portal can be described as a tool that provides unique interface toward information located in various parts of an information system. It includes a big number of services that enable access and information retrieval, development of communities, collaboration, commerce and other advantages [3].

Portals connect users not only with things that are needed, but with other users too. Further, they provide tools that are used for collaborative work. It means that services, such as email, workflow and desktop applications, even critical business applications, should be provided via portal [4].

Key advantages of a portal are reflected in: simpler retrieval, analysis and organization of business information, according to business needs and aims. Integrated user interface is used both for information presentation and for interaction with the user.

\section{B. Digital identity management}

Requirements and limitations of a distributed information system lead to a solution that is based on digital identity management through integrated, efficient and centralized infrastructure. This concept of network services and technologies enables $[5,6,7]$ :

- $\quad$ secure access to all resources;

- more efficient control of access to resources;

- prompt change of the relations between identities and resources;

- protection of confidential information from unauthorized access.

The goal of the system for digital identity management is to implement a relationship between identifiers of various services, so as to integrate information about the user with the identifier. Accordingly, digital identity management system integrates business processes, security policies and technologies that help digital identities management, as well as the control of access to resources [8].

\section{Adaptive system for information management}

According to Oxford Advanced Learner's dictionary, the term adaptive is defined as a "possibility for changing when it is needed in order to adapt to different situations" [9].

Work environment is adaptive if it is able to:

- Track users' activities;

- Interpret them in the basic sectors of specific models;

- Conclude on the user's needs and preferences apart from the interpreted activities, appropriately representing the above-mentioned model;

- Act on the available knowledge on its users and dynamically manage the business process.

In the context of e-document management, adaptive systems are more specialized and focused on content adaptation and presentation. They take the following issues into account: users' activities, users' adaptation of the system, cognitive structures and context of documents and available materials [9, 10, 11]. Figure 2 shows the structure of an adaptive system. 


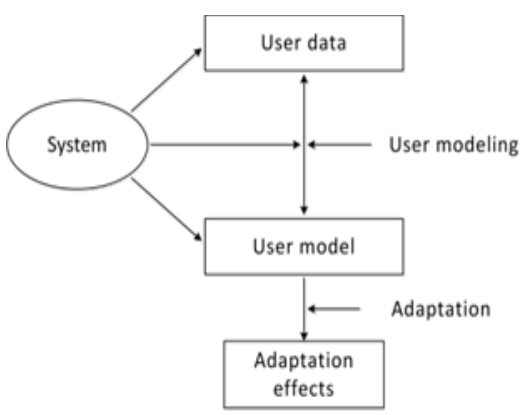

Fig. 2. Structure of an adaptive environment

A system goes through three phases during the process of adaptation. It controls the process of user data acquisition, the creation of user model and the process of adaptation. Particular information about the user is required in order to implement the system behavior in accordance with the user's needs.

\section{Business intelligence}

Business intelligence is one of the most used terms for information support in decision making. It is a component of the organizational information system, developed in order to enable KPI management. Organization performance management requires comprehensive and timely information about KPIs [12, 13].

Steve Mutfitt defines business intelligence as follows:" Business intelligence is a way of delivering the right information in the right format to the right people at the right time. A good business intelligence system collects information from all parts of the organization, analyzes them, prepares the necessary reports and sends them to people who need them. In this way, each individual receives information tailored to their needs." [14]

Figure 3 presents the main elements of the business intelligence system.

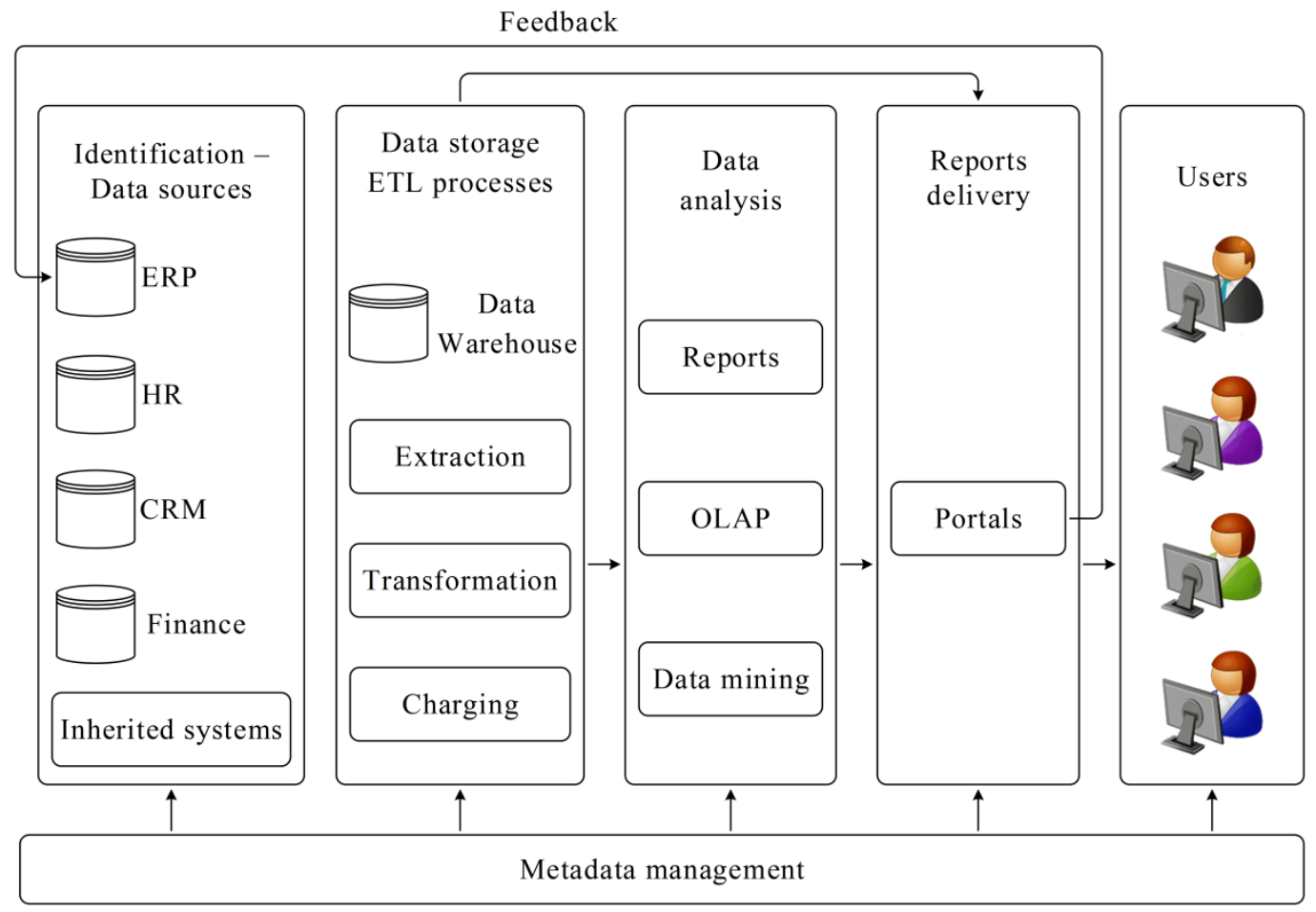

Fig. 3. Main elements of the business intelligence system

\section{Problems We ARe Trying To Solve With INFORMATION MANAGEMENT SYSTEM}

A large number of analyses and statistics show the following indicators which significantly impact the productivity and efficiency of business systems:

- The employee spends up to 25 minutes of their working time every day in searching for needed information. In that way we come to a calculation that one company with 1000 employees wastes 25000 minutes, i.e., 416.6 hours every day. If we multiply these hours with the price of a working hour, we come to an amount of money which is a daily financial loss of company.
Calculations on an annual level show a drastic financial loss.

- Near the half of employees store confidential business information on mobile phones. This is a great security risk. Not much knowledge is needed to access this information. Also, security risk is storage of business information on tablets, laptops, private clouds, external hard discs and other mobile devices.

- Communications between employees is bad and nonstandardized. Often many different tools are used (Skype, Viber, WhatsApp,...) which leads to decreasing collaboration and service quality. The quality of service suffers because it is hard to find information. 
- A significant number of employees do not realize dependencies between information and company profit. Employees are often in situations to fill in some reports without understanding their importance and purpose. In that case we come to a logical question of how to submit a report with good and high-quality information if someone does not believe in its importance. The lack of the education for concrete job can be a reason for this.

- A lack of investments for permanent education of employees depreciates the value of investments in new technology. Disorganized education for using new application packages affects the efficiency of using programs for office operations or complex CRM or ERP systems. The lack of employees' education is one of the major reasons for an inefficient implementation of program packages. Expensive program packages implemented in information system with a goal to improve efficiency and productivity are not used to the extent that they should, because employees lack appropriate knowledge. A large percentage of employees do not use all functionalities of program packages. Many of them do not know what is available for usage.

- Good collaboration increases the company efficiency. Because of lack of information exchange and collaboration, several employees do the same thing at the same time. This way of work increases the number of needed employees and costs, at the same time reducing information security.

- One big problem in business system is the lack of a defined way for information storage, especially for unstructured data. Also, a widespread problem is the fact that there is no standard for naming files and documents.

\section{DEVELOPMENT OF INFORMATION MANAGEMENT SYSTEM MODEL BASED ON PRINCIPLES OF ADAPTIVITY AND PERSONALIZATION}

One of possible efficient solutions for the above problems is the implementation of the Information Management System (IMS) based on principles of adaptability and personalization.

\section{A. Model of the web portal for the information management}

Examples of available information management systems realized by creating and integrating additional adaptive functionality to existing document management systems are Microsoft SharePoint and Alfresco. The disadvantages of these solutions are the following:

- These systems have the task of providing adaptive functionality, which often do not fit the individual processes.

- Systems are not interoperable because they are each developed as an isolated application that cannot share resources or user information.

- Basic services of the system for management of edocuments are more complex in adaptive systems, hence, prior knowledge about the system is required.

- There are no basic services related to communication and social interaction between users in the electronic exchange of documents.

Figure 4 presents a model of the web portal for the information management with its elements.

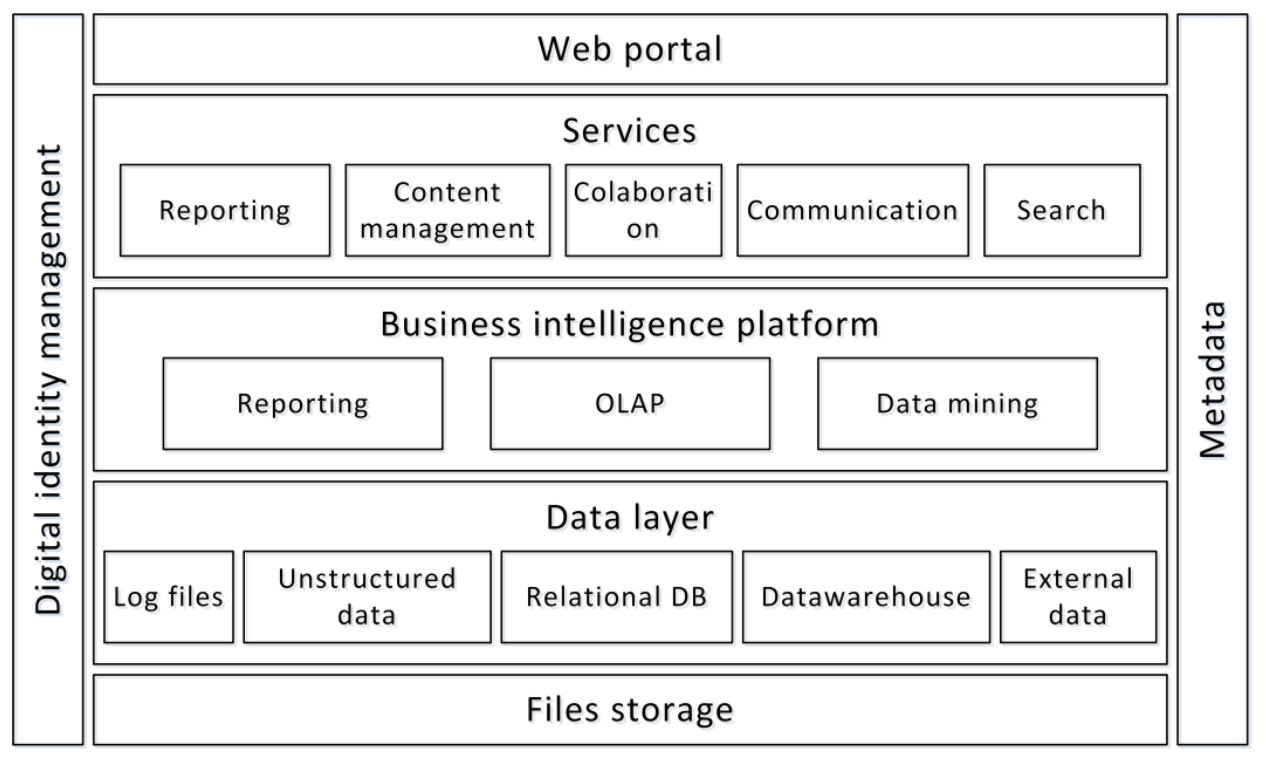

Fig. 4. Model of information management system based on principles of adaptability and personalization

\section{B. Authentication - adaptation - personalization}

The process that starts with the authentication of users, and continues with the process of adaptation according to defined criteria ends with the review of personalized content and available web services of the portal (Figure 5) [15]. 


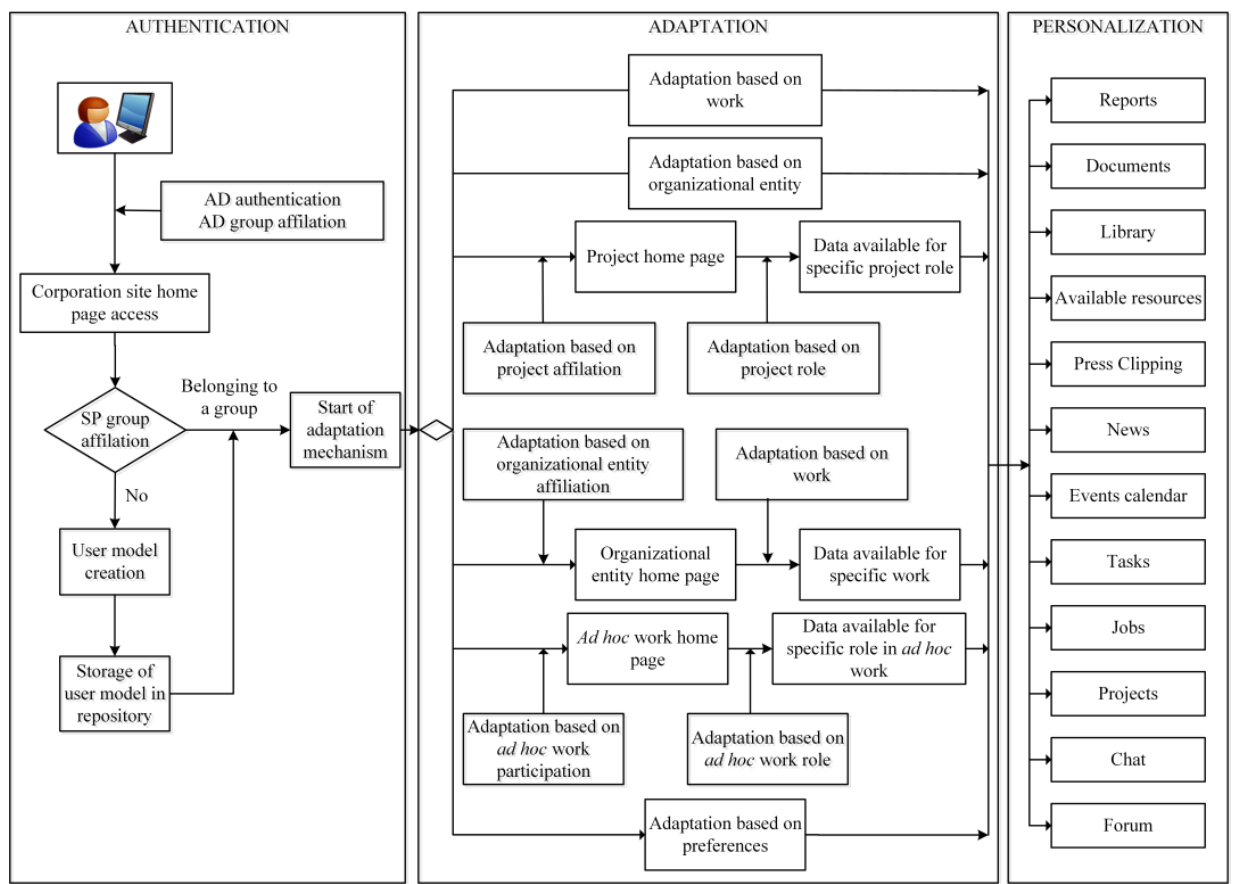

Fig. 5. Process of authentication, adaptation and personalization

Adaptability is enabled not only for the portal user, but also for the devices for access. In case of smart phones and similar devices, the portal automatically adjusts the content and view format.

\section{Cooperation of the portal users by using web services}

Figure 6 shows users of different organizational units and their interaction during the exchange of e-documents and information using local shareable web folders and the portal for intelligent management of e-documents for exchange of emails via mail server [15].

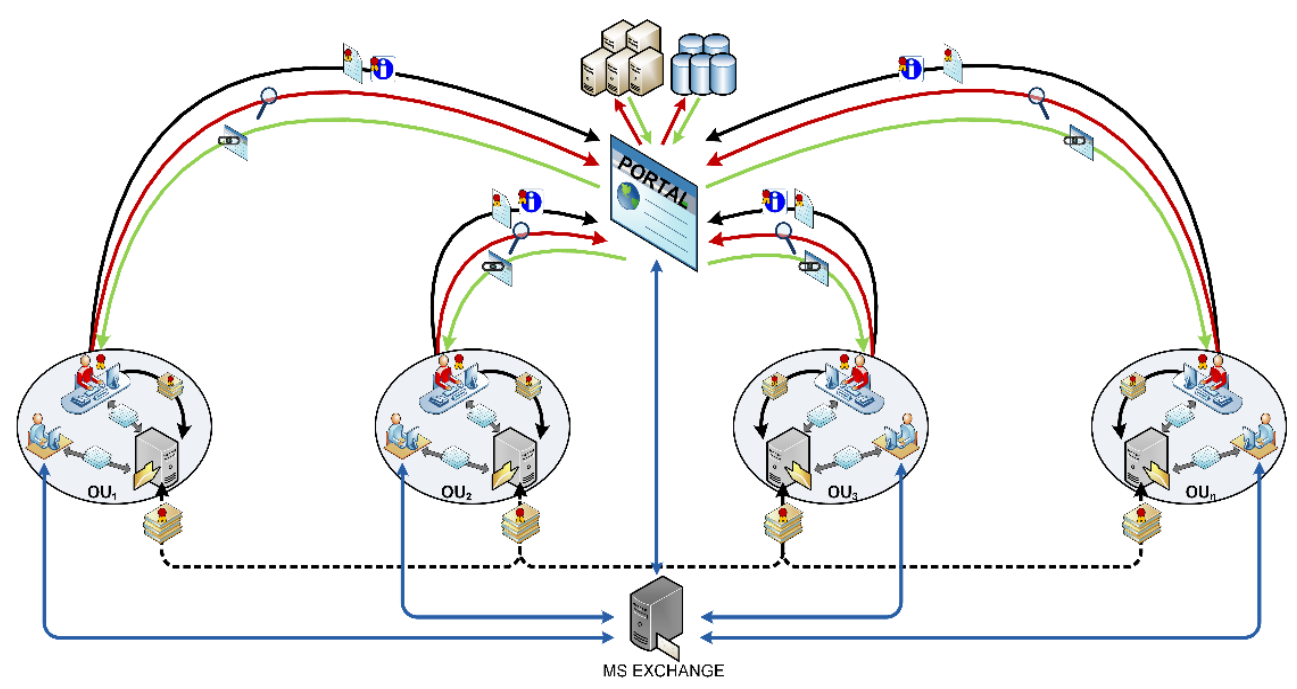

\begin{tabular}{|c|c|c|c|}
\hline $\begin{array}{l}\text { LEGEND } \\
\longrightarrow \text { PUBLISHING } \\
\rightarrow \text { REPLICATION } \\
\longrightarrow \text { QUERY } \\
\longrightarrow \text { ANSWER } \\
\longrightarrow \text { INFORMATION EXCHANGE } \\
\longleftrightarrow \text { DOCUMENT EXCHANGE }\end{array}$ & $\begin{array}{l}\text { DOCUMENT } \\
\text { LARGE DOCUMENTS } \\
\text { (1NFORMATION } \\
8 \text { VERIFICATION } \\
\rho \text { QUERY } \\
\text { HTIML PAGE WITH/ WITHOUT LINK }\end{array}$ & $\begin{array}{l}\text { LINK } \\
\text { ORGANIZATIONALUNIT } \\
\text { ATH APPROVER } \\
8 \text { EMPLOYEES } \\
\text { PORTAL GROUP OU }\end{array}$ & $\begin{array}{l}\text { PORTAL } \\
\text { FILE SERVER OU } \\
\text { MS EXCHANGE } \\
\text { FILE SERVERS } \\
\text { DATABASES }\end{array}$ \\
\hline
\end{tabular}

Fig. 6. Collaboration among portal users by using web services on the level of organizational units 


\section{IMPLEMENTATION AND APPLICATION OF DEVELOPED} Model OF INTELLIGENT MANAGEMENT OF E-DOCUMENTS

By applying a model which consists of: collecting data, data exploration, classifying users, content and service adaptation, portal usage and defining goals, the model of portal for intelligent management of e-documents is implemented (Figure 7) [16].

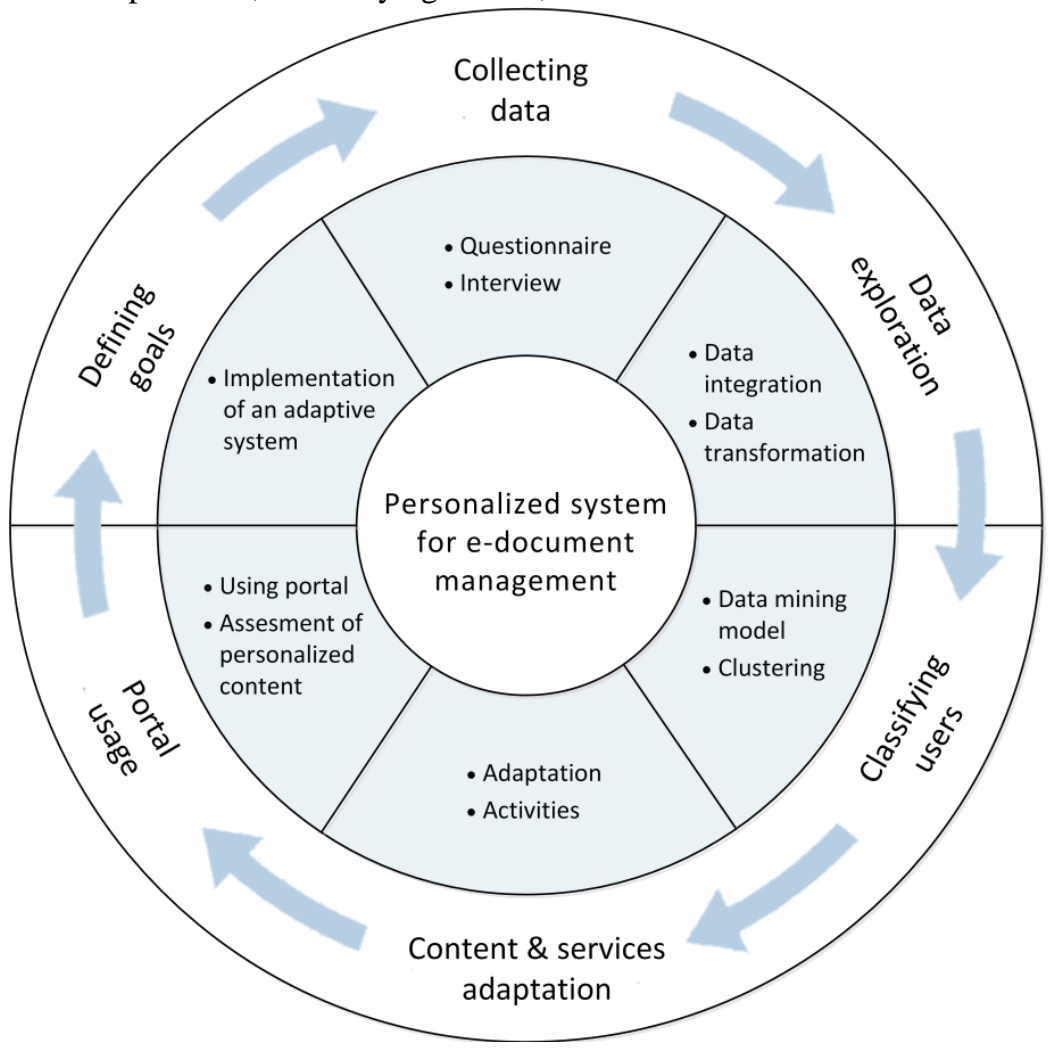

Fig. 7. Realization flow graphics view of portal for intelligent management of e-documents model

Collecting and researching users' data in the portal for intelligent management of e-documents can be managed from:

- questionnaires;

- different databases;

- different $\log$ files;

- interview.

Information about the documents, user groups, business processes, projects and applications are stored in:

- Document database: types of documents, document metadata.

- Groups on AD and SP: structure and group names; authorization at the group level.

- Database of business processes: specification of business processes.

- Project database: specification of projects in the phase of realization.

- Application database: specification of internally developed applications; specification of external application.
- Log files of the operating system: the number of access locations, the number of documents per location; commonly accessed sites; most users accessing the portal and other.

One of the main functionalities of the portal for intelligent management of e-documents is a possibility of an adaptable and personalized view of information and reports intended for different levels of the hierarchical management.

Figure 8 shows a pyramid with a chronological view of processes of assigning, realization and reporting related to assignments. Hierarchical levels of management are shown with different shades of grey colour. According to hierarchy, the general director and a deputy general manager are coloured in the darkest grey, while the executive officers, directors of directorates, directors of sectors, heads of departments and the perpetrators are coloured in the lighter colours of grey.

Information is marked with ellipses. Grey ellipses present a view of personalized information intended for employers of certain hierarchical levels and by job type, while white ellipses present information related to some reports, news, assignments and are used to inform other employees [15]. 


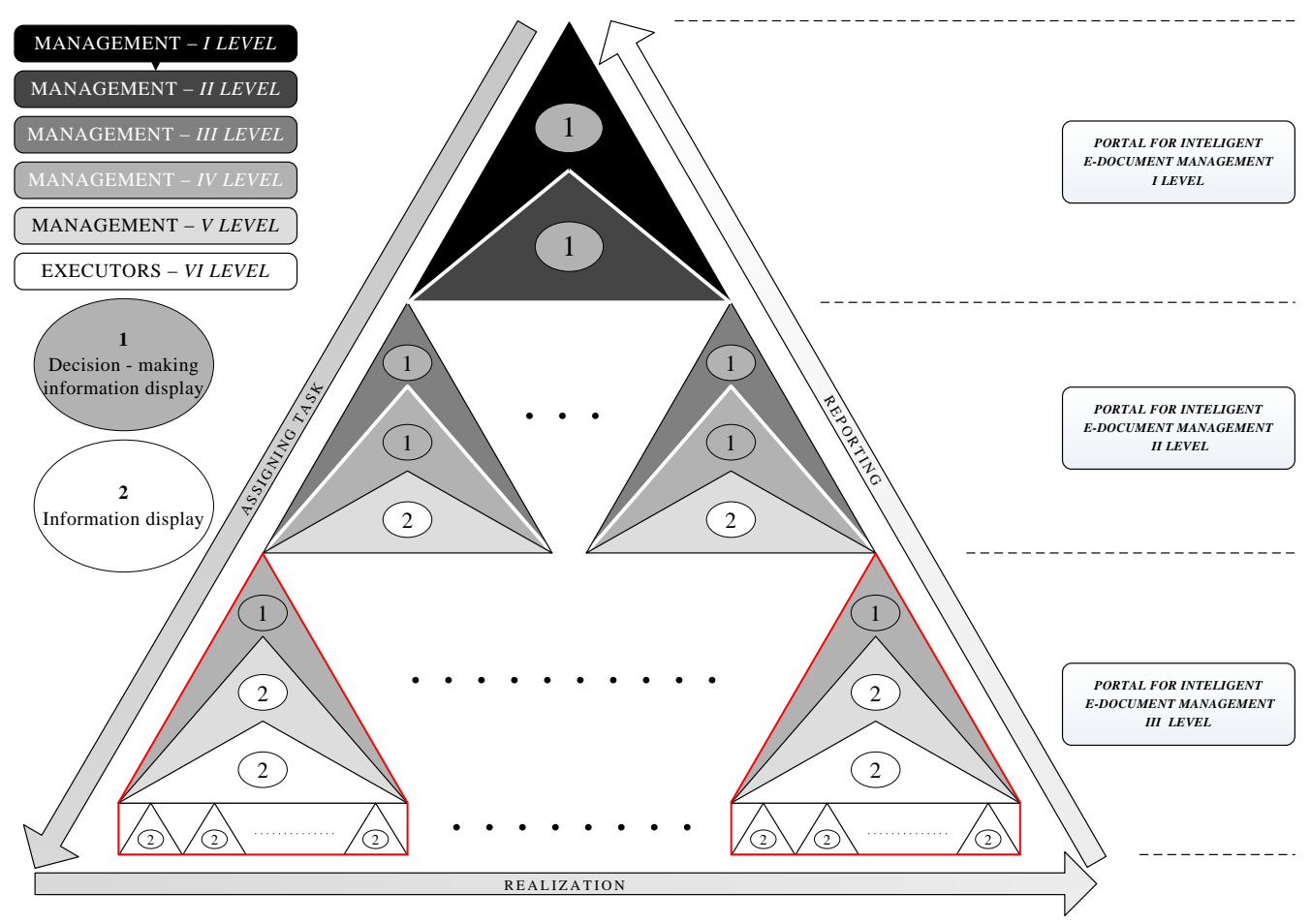

Fig. 8. Model of the job realization flow and adaptive view of the information and reports on the portal for intelligent e-document management

Figure 9 shows a personalized report for the director of the sector (fourth hierarchical level) on web portal for intelligent management of e-documents. The report page consists of textual, tabular and graphic reports and KPI reports for all offices in the scope of the sector. This inspected view of report enables quick response and decision making.

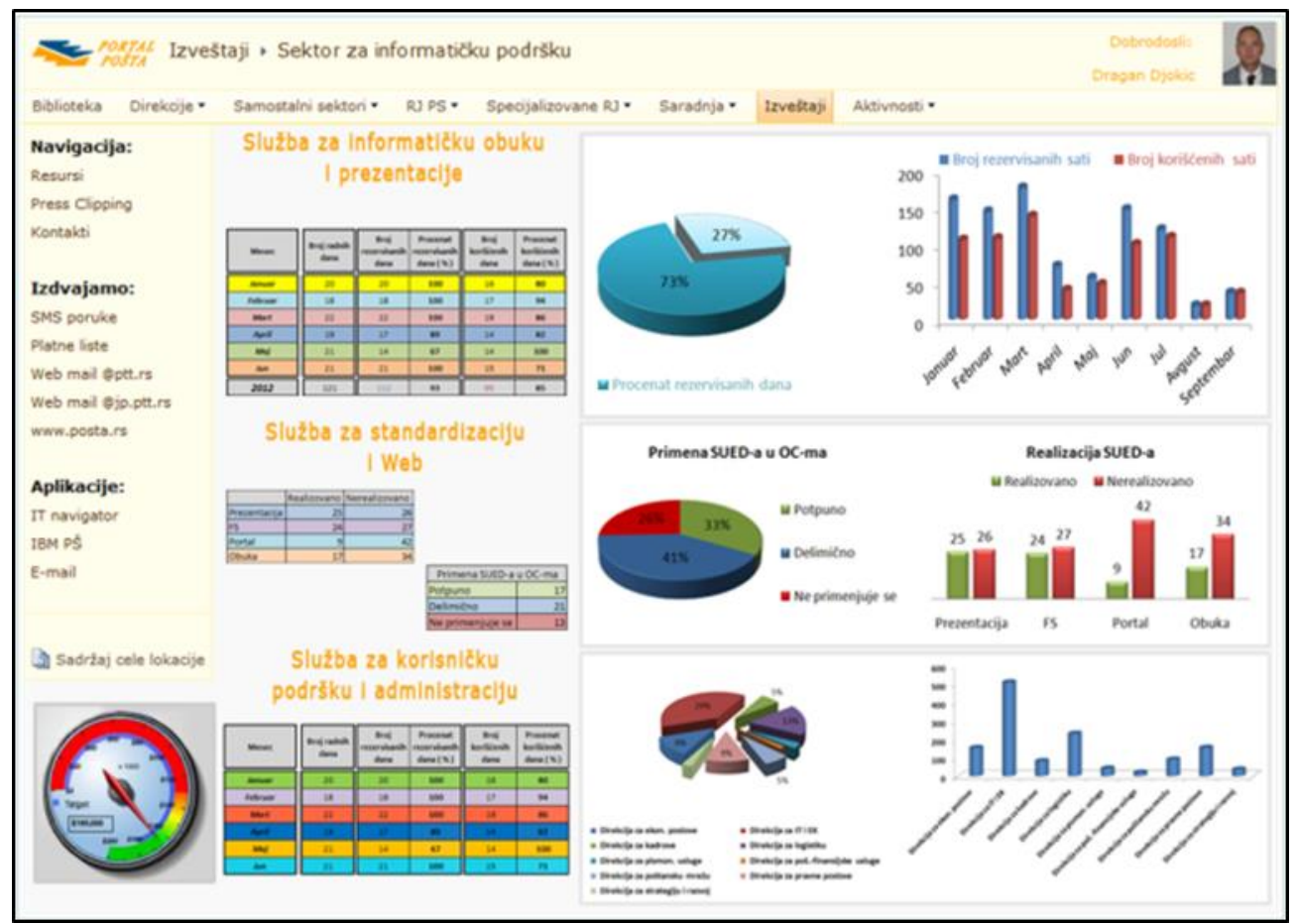

Fig. 9. Personalized business intelligence report for the director of the fourth hierarchical level on the portal for intelligent management of e-documents

Adaptation mechanisms for the information management system can be improved by using ontologies and semantic web concepts. Communication between system components should be carried out completely by using web services. Also, stereotype models used for content adaptation in business processes should be improved.

The paper opens possibilities for further research, which relate to the use of business intelligence in adaptive 
information management systems. In business intelligence area, new techniques and tools should be explored, which can contribute to obtaining additional information and knowledge about user model characteristics.

The end goal of further research is a complete adaptive and personalized information management system, which enables automation of business process workflows realization.

\section{CONCLUSION}

Information and document management may not yet be recognized yet as a priority one in large business systems, but it has a large potential and impact on business process transformation. Business process analyses can help conclude whether they are paper based and whether it is possible to digitalize them.

In order to provide timely and correct information to employees, business process owners and managers who make decisions upon them, there must be implemented an adequate information management system based on adaptability and personalization. That kind of system leads necessarily to business process transformation and makes connection between people, technology, systems and business practice.

Market is a very dynamic category which continually changes. If a company wants to have a leader position on the market, it is necessary that it should improve its business through the following activities:

- Realization of planned productivity;

- Ensuring security;

- Development and implementing of collaboration;

- Development of a planning company approach to customers.

Who is important for the realization and success of the above activities? In the first place, it is people on managerial positions. IT leaders are faced with unique challenges while fulfilling core business demands, and this assumes a constant growth of business. Implementation of new technology which changes rapidly can be seen as aggravating or mitigating circumstances, depending on manager capabilities.

The company can overcome the challenges of information management and ensure success working on the following principles:

- Promoting awareness about importance of available information with the help of permanent education in order to apply operative efficiency into the company DNA.

- Standardizing processes and policies for data storage using technical solutions, which leads to establishing a stable Information Management.

- Strengthening collaboration and information and document exchange by opening communication between employees from different organizational and functional levels. Exchange of clear information improves internal efficiency and provides a positive impact on the customer, who recognizes a faster, better and more concrete service provided from the company that is focused on communication improvement.

- Providing secure future by investing in Information Management System which is adaptive and personalized for every customer. This is necessary to keep pace with information and challenges growth.

- Permanent development in the area of information security.

Today, the company whose top management has relevant information wins in the market game. This is because of the possibility to make timely decisions or the possibility to spend more time in analyzing information relevant for making decisions.

The main hypothesis developed and proved in the paper is that an implementation of information management system based on principles of adaptability and personalization leverages electronic content management, users' interactivity and collaboration. This leads to an efficient exchange of information at all hierarchical levels, as well as reporting and measuring mechanisms, such as business intelligence elements and key performance indicators. The basic role of the information management system based on principles of adaptability and personalization in this research is reflected in the integration of heterogeneous e-document management system components and services for adaptation. Integration includes human resources, information, processes and application components

In the experimental part, research was carried out in order to validate the proposed model for designing and implementation of an information management system based on principles of adaptability and personalization. The results showed that information management system's services, implemented adaptive mechanisms and their integration with the system for document management contributed to better outcomes, improved level of collaboration and document standardization, fostered and transformed business processes, led to cost reduction eliminating the need for document printing, improved system security and efficient document exchange.

A developed information management system allows for the integration of different components and services of ebusiness, such as: adaptation services, services for management of e-documents, services for communication and cooperation of systems' users, reporting services, mobile services etc.

Implementation of an information management system in cloud computing environment enabled scalability, reliability and dislocation of the system, which improved the implementation of business processes within the company.

The results showed that the application of services of information management system, implemented adaptive mechanism and its integration with the system for management of e-documents achieve better results and greater satisfaction of users, and increase the efficiency and effectiveness of all users of the portal. 
The results of this paper open the door for further research in the area of information management system development, through an integration of a larger number of services that ensure different functionalities and additionally provide adaptability. Improvements of the described model can be considered as contributing to the development of sophisticated adaptation mechanisms and advanced services for key business processes support.

Adaptation mechanisms for information management system can be improved by using ontologies and semantic web concepts. Communication between system components should be carried out completely by using web services. Also, stereotype models used for content adaptation in business processes should be improved.

The paper opens possibilities for further research in relation to the use of business intelligence in adaptive information management systems. In the business intelligence area, new techniques and tools should be explored, which can contribute to obtaining additional information and knowledge about user model characteristics.

The end goal of further research is an integrated adaptive and personalized information management system, which enables automation of business process workflows realization.

\section{REFERENCES}

[1] D. Đokić, A. Labus, S. Jevremović, A. Stokić and A. Milić, "Portal for the management of digitally signed electronic documents", Metalurgia international, Vol.: 17, No.: 9, pp.: 120-129, 2012.

[2] D. Đokić and D. Bečejski Vujaklija, "Adaptive access to the information in large business systems", University Metropolitan, Seventh Annual Conference BISEC, 2015, Belgrade, Serbia, pp. 30-37, 17 June, 2015, available at: http://bisec.rs/en/conference-programme/ (accessed 26 June, 2015).

[3] J. M. Raol, K.S. Koong, L.C. Liu and C.S. Yu, "An identification and classification of enterprise portal functions and features", Industrial Management \& Data Systems, Vol.: 102, No.: 7, pp.: 390-399, 2002.

[4] B. Ives, "Gartner's Magic Quadrant for Intranet Portals", 2012, available at: http://billives.typepad.com/portals_and_km/2008/11/toby-wardrecently-shared-the-highlights-of-the-gartners-magic-quadrant-forintranet-portals-first-this-is-a-consolidati.html, (accessed 26 June, 2015).
[5] J. Yong, "Digital Identity Design and Privacy Preservation for eLearning", In: Swinburne University of Technology. 11th International Conference Computer Supported Cooperative Work in Design. Melbourne, Australia, pp.: 858 - 863, 26-28 April, 2007.

[6] Y. Zhang and J.L. Chen, "A Delegation Solution for Universal Identity Management in SOA", IEEE Transactions on Services Computing, Vol.: 4, No.: 1, pp.: 70-81, 2011.

[7] S. Popović, A. Njeguš, M. Vulić, D. Đokić and Đ. Mazinjanin, “ Service oriented framework for system interoperability modeling", Metalurgia international, Vo.: 17, No.: 11, pp.: 171-17, 2012.

[8] D. Recordon and D. Reed, "Open ID 2.0: a platform for user-centric identity management", In: Association for Computing Machinery. 13th ACM Conference on Computer and Communications Security 2006. Alexandria, VA, USA, 30. October-3. November, ACM: New York, pp.: 11-16, 2006.

[9] P. Brusilovsky and M. T. Maybury, "From adaptive hypermedia to the adaptive web", Communications of the ACM, Vol.: 45, No.: 5, pp.: 3033, 2002.

[10] C. Gutl and F. Modritscher, "Towards a Generic Adaptive System applicable for Web-based Learning Management Environments", In: ABIS. 13th Annual Workshop of the SIG Adaptivity and User Modeling in Interactive Systems ABIS 2005. Saarbrücken, pp.: 1-6, 10-12 October, 2005.

[11] D. Đokić, M. Despotović-Zrakić, D. Barać and K. Simić, "Document management system for e-government", In Uroš Pinterič, Lea Prijon (Ed.), Selected issues of modern democracy, Ljubljana: Založba Vega, pp.: 277-292, 2012.

[12] T. Anderson and F. Elloumi, "Theory and Practice of Online Learning", Edmonton: Athabasca University, 2004.

[13] A. R. Anaya and J. G. Boticari, "Content-free collaborative learning modeling using data mining, User Modeling and User-Adapted Interaction", Vol.: 21, No.: 1-2, pp. 181-216, 2011.

[14] Y. Atif, R. Benlamri and J, Berri, "Dynamic Learning Modeler", Journal of Educational Technology \& Society, Vol.: 6, No.: 4, pp. 60-72, 2003.

[15] D. Đokić, "Model of portal for intelligent management of electronic documents", Ph.D Dissertation, Faculty of Organizational Sciences, University of Belgrade, 2012.

[16] M. Despotović-Zrakić, A. Marković, Z. Bogdanović, D. Barać and S. Krčo, "Providing Adaptivity in Moodle LMS Courses", Journal of Educational Technology \& Society, Vol.: 15, No.: 1, pp.: 326-338, 2012, available at: http://www.ifets.info/journals/15_1/28.pdf , (accessed 26 June, 2015). 